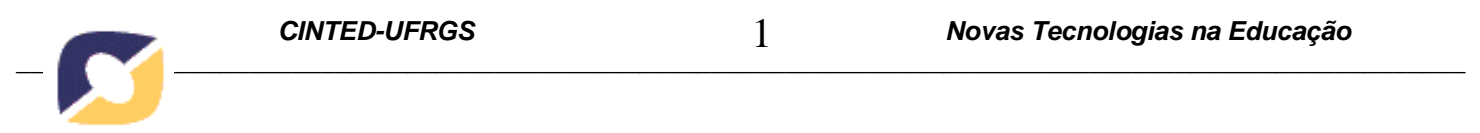

\title{
Contribuições da Teoria da Aprendizagem Multimídia e da Usabilidade para aprendizagem de Libras e Língua Portuguesa por meio de aplicativos móveis
}

Maristela Compagnoni Vieira, PPGIE/UFRGS, maricompagnoni@gmail.com

Ygor Corrêa, PPGIE/UFRGS, y.correa@bol.com.br

Jean Felipe Patikowski Cheiran, UNIPAMPA, jfpcheiran@gmail.com

Lucila Maria Costi Santarosa, PPGIE/UFRGS, lucila.santarosa@ufrgs.br, Maria Cristina Villanova Biasuz, PPGIE/UFRGS, mcbiazus@ufrgs.br

Resumo: O recente surgimento de aplicativos brasileiros tradutores automáticos de Língua Portuguesa para Libras desencadeou a realização de diálogos com sujeitos surdos e ouvintes, a fim de discutir a validade social e tecnológica dessas ferramentas. Frente a essa interação com os usuários, percebeu-se que esses utilizavam os aplicativos não apenas como tradutores, mas também como objetos para a aprendizagem de segunda língua. A partir dessa constatação, os aplicativos HandTalk e ProDeaf Móvel foram analisados com base na Teoria da Aprendizagem Multimídia e em heurísticas de usabilidade. Os resultados apresentam um conjunto de sugestões que, se incorporadas aos aplicativos dessa natureza, podem contribuir para redução de problemas de interface e de interação, de modo a contemplar os interesses de seus usuários e garantir a qualidade de uso.

Palavras-chaves: Libras, Tecnologia Assistiva, Tradução Automática, Aprendizagem Multimídia, Usabilidade.

\section{Contributions of the Multimedia Learning Theory and Usability to learning Libras and Portuguese through mobile applications}

Abstract: The recent launching of Brazilian apps, which are automatic translators of Portuguese into Brazilian Sign Language (Libras) triggered the establishment of dialogues with deaf and hearing individuals, in order to discuss the social and technological validity of these tools. Related to this interaction with users we realized that these users use the apps not only as translators, but also as objects for learning a second language. From this observation, Handtalk and ProDeaf apps were analyzed based on the the Theory of Multimedia Learning and and usability heuristics . The results presenta set of suggestions that if incorporated to the apps of this nature can contribute to the reduction of interface and interaction problems, , in order to contemplate the interests of their users and to ensure the quality of use.

Key Words: Brazilian Sign Language, Assistive Technology, Automatic Translation, Multimedia Learning, Usability.

\section{INTRODUÇÃO}

Sob a ótica sociointeracionista, a língua é considerada uma ferramenta psicológica capaz de mediar a atividade humana e o refinamento das estruturas psicológicas superiores (Vygotski, 1997). Devido a isso, apresenta funções que transcendem o ato dialógico, pois "a linguagem não apenas cumpre função comunicativa (...) mas também é instrumento do pensamento” (Vygotsky, 1997, p. 120). Na perspectiva linguística proposta por Benveniste (1989) entende-se que a língua natural, antes de servir para comunicar, serve para viver. Cabe ressaltar que, uma vez que o signo linguístico é social e ideológico, a apropriação do léxico da língua é um aspecto primário da construção da identidade (Bakhtin, 2006). 
Oficialmente considerada língua oficial da comunidade surda nacional (Brasil, 2002), a Língua Brasileira de Sinais (Libras), como qualquer outra, desempenha a seus usuários funções que ultrapassam o ato da comunicação e ocupa papel de destaque na mediação da interação desses sujeitos com o mundo. Diante disso, percebe-se a importância de possibilitar às pessoas surdas processos de interação que possam ser estabelecidos em sua língua materna, em vez de sujeitá-las à oralização e/ou à leitura labial da Língua Portuguesa, outrora impostas (Capovilla e Capovilla, 2002; Quadros, 2003, 2008).

Com base em tais pressupostos, nota-se a relevância de estratégias que viabilizem a comunicação entre surdos e ouvintes, escopo no qual se inserem ferramentas digitais de tradução automática da Língua Portuguesa para a Libras que, na condição de Tecnologia Assistiva (TA), objetivam a promoção da autonomia e da participação de pessoas com deficiência nos mais variados espaços sociais (Santarosa e Conforto, 2010; Barth e Santarosa, 2007).

A utilização de ferramentas digitais pode permitir o acesso a microcosmos sociais limitados aos sujeitos que dominam seu código linguístico, como é o caso da Libras para sujeitos ouvintes; ou da Língua Portuguesa, para os sujeitos surdos. Relativo a isto, ferramentas de tradução automática da Língua Portuguesa para Libras, como os aplicativos brasileiros HandTalk e ProDeaf Móvel, podem ampliar as interações linguísticas de círculos antes restritos a ouvintes ou surdos por meio de contratos conversacionais estabelecidos com mediações tecnológicas.

Estudos anteriormente realizados, a fim de analisar a validade social de aplicativos tradutores automáticos de Língua Portuguesa para Libras (Corrêa et al., 2014; Vieira et al., 2014), permitiram identificar que a principal função atribuída pelos usuários, surdos e ouvintes, aos aplicativos referia-se à possibilidade de aprendizagem de uma ou ambas as línguas envolvidas na tradução. Observou-se, portanto, que na perspectiva do público-alvo de tais ferramentas, sua principal validade reside em sua potencialidade como mediadora da aprendizagem da Língua Portuguesa, como segunda língua para os sujeitos surdos, e igualmente da Libras, para os sujeitos surdos e ouvintes. Constatou-se, com isso, que os usos que os sujeitos ouvintes e/ou surdos fazem dessas ferramentas não referem-se apenas ao objetivo inicial proposto pelos desenvolvedores dos aplicativos, condição essa que amplia o escopo de suas finalidades, permitindo seu entendimento não apenas como tradutores, mas também como meio para a aprendizagem.

Diante do exposto, conduziu-se o presente estudo que, ao analisar os usos evidenciados pela comunidade de usuários de aplicativos tradutores automáticos de Língua Portuguesa para Libras, objetiva apresentar sugestões que permitam ampliar o caráter mediador e pedagógico dessas ferramentas e corrigir problemas de interação com os usuários, com base nos pressupostos da Teoria da Aprendizagem Multimídia e da Avaliação Heurística de usabilidade.

\section{COGNIÇÃO HUMANA E RECURSOS DIGITAIS DE APRENDIZAGEM}

Observa-se na atualidade um aumento da gama de materiais digitais de natureza educacional, entretanto, muitos desses recursos não são elaborados de maneira a promover uma aprendizagem significativa (Mayer e Moreno, 2002), uma vez que não consideram algumas características essenciais do processo cognitivo dos estudantes (Santos e Tarouco, 2007). Diante desse panorama, a Teoria da Aprendizagem Multimídia (Mayer e Moreno, 2002; 2003) estabelece que o ser humano percebe mensagens sonoras e imagéticas por meio de dois diferentes canais de processamento, representados pelos modos verbal e 
pictórico. A combinação das informações obtidas pelos dois diferentes canais com os conhecimentos prévios do sujeito é que poderá se transformar em um conhecimento armazenado na memória de longo prazo.

Partindo dessa premissa, Mayer e Moreno (2002; 2003) desenvolveram um conjunto de diretrizes aplicáveis ao desenvolvimento de materiais voltados à aprendizagem por meio de sistemas computacionais, as quais são apresentadas no Quadro 1.

Princípio da Contiguidade: animações e narrações devem ser apresentadas de maneira complementar e contígua.

Princípio da Coerência: elementos como palavras, imagens ou sons estranhos ou desnecessários competem com o conteúdo relevante nos canais de processamento cognitivo.

Princípio da Modalidade: a apresentação de animações e textos escritos de maneira concomitante pode sobrecarregar a memoria de processamento visual.

Princípio da Redundância: uma animação narrada concisa pode ser menos efetiva à aprendizagem quando se inclui texto escrito concomitante.

Princípio da Multimídia: animações narradas são mais efetivas para a aprendizagem do que apenas narrações.

Quadro 1: Resumo dos princípios da Teoria da Aprendizagem Multimídia (Mayer e Moreno, 2002)

De maneira geral, depreende-se desses princípios que estudantes aprendem mais significativamente quando suas memórias de trabalho, visual e/ou verbal não estão sobrecarregadas e também quando os canais de processamento visual e verbal são igualmente estimulados em uma relação síncrona de correspondência e contiguidade. A observância desses princípios, aliados a uma interface simples, eficiente e atrativa, resulta em recursos digitais mais adequados à mediação de aprendizagens significativas.

\section{USABILIDADE}

A qualidade de uma interface de usuário é atributo fundamental, dado que essa é a única porção de um sistema computacional com a qual o utilizador entra em contato (Moran, 1981). Esses aspectos de interação e interface são objeto de estudo da área denominada Interação Humano-Computador (IHC), e uma qualidade de software amplamente discutida nela é a usabilidade.

As normas ISO/IEC 9126 (1991) e ISO 9241-11 (1998) definem usabilidade, respectivamente, como "a capacidade do produto de software ser compreendido, aprendido, usado e atrativo para o usuário quando usado sob condições específicas” e “a extensão na qual um produto pode ser usado por usuários específicos para atingir objetivos específicos com eficiência, eficácia e satisfação em um contexto específico de uso”. Nielsen (2012), por sua vez, descreve usabilidade como "um atributo de qualidade que avalia quão fácil é usar uma interface com usuário” e a separa em cinco componentes: facilidade de aprendizado, eficiência na realização das tarefas, facilidade de memorização da utilização, facilidade de entender e se recuperar de erros, e satisfação durante o uso.

A despeito de seu conceito formal, diversos estudos procuraram estabelecer critérios e diretrizes voltados à avaliação de usabilidade em interfaces (Bastien e Scapin, 1993; Nielsen, 1994). Neste trabalho, foram utilizadas dez heurísticas para um bom design de interface estabelecidas por Nielsen (1994), denominadas heurísticas de usabilidade e sumarizadas no Quadro 2.

Visibilidade do estado do sistema: O sistema deve sempre manter usuários informados sobre o que acontece por meio de feedback apropriado e em tempo razoável. 
\begin{tabular}{|l|}
\hline $\begin{array}{l}\text { Correspondência entre o sistema e o mundo real: O sistema deve utilizar a linguagem dos usuários, com } \\
\text { palavras, frases e conceitos familiares a eles, em vez de termos orientados ao sistema. }\end{array}$ \\
\hline $\begin{array}{l}\text { Controle e liberdade do usuário: Os usuários muitas vezes escolhem funções por engano e precisam de } \\
\text { "saídas de emergência". O sistema deve permitir comandos de desfazer e refazer. }\end{array}$ \\
\hline $\begin{array}{l}\text { Consistência e padrões: A plataforma deve seguir convenções e não devem ser apresentados termos ou } \\
\text { palavras diferentes com uma mesma função. Deve-se seguir os padrões da plataforma. }\end{array}$ \\
\hline $\begin{array}{l}\text { Prevenção de erros: Deve-se eliminar as condições passíveis de erros e apresentar aos usuários uma opção } \\
\text { de confirmação antes de se comprometer com ação. }\end{array}$ \\
\hline $\begin{array}{l}\text { Reconhecimento em vez de lembrar: Objetos e opções devem estar visíveis para que o usuário os } \\
\text { reconheça em vez de recordar o procedimento. As instruções devem ser facilmente recuperáveis. }\end{array}$ \\
\hline $\begin{array}{l}\text { Flexibilidade e eficiência no uso: Aceleradores podem tornar mais rápida a interação para o usuário } \\
\text { experiente. Permitir aos usuários a personalização de ações frequentes. }\end{array}$ \\
\hline $\begin{array}{l}\text { Design estético e minimalista: Os diálogos não devem conter informação irrelevante ou raramente } \\
\text { necessária. Cada unidade extra de informação compete com as relevantes e diminui sua visibilidade. }\end{array}$ \\
\hline $\begin{array}{l}\text { Ajudar usuários a reconhecer, diagnosticar e se recuperar de erros: As mensagens de erro devem ser } \\
\text { expressas em linguagem clara, indicar o problema e sugerir uma solução construtiva. }\end{array}$ \\
\hline $\begin{array}{l}\text { Ajuda e documentação: Embora seja melhor que o sistema possa ser usado sem documentação, pode ser } \\
\text { necessário fornecê-la. Qualquer informação deve ser fácil de pesquisar, focada na tarefa do usuário como } \\
\text { uma lista de passos, e não ser muito grande. }\end{array}$ \\
\hline
\end{tabular} Quadro 2: Heurísticas de usabilidade resumidas (Nielsen, 1994).

\section{METODOLOGIA}

Esta é uma pesquisa qualitativa (Moraes, 2003), na qual foram aplicadas três metodologias consecutivas e complementares, a fim de estabelecer: (a) aspectos relacionados à validade social de Tecnologias Assistivas mediadoras da comunicação entre sujeitos surdos e ouvintes, notadamente no que tange à aprendizagem de Língua Portuguesa e/ou Libras por meio de tais ferramentas e; (b) contribuições de teorias relacionadas à aprendizagem multimídia apoiada em sistemas computacionais e à usabilidade quanto ao desenvolvimento e aprimoramento de sistemas tradutores automáticos de Língua Portuguesa para Libras.

O estudo contou com a participação de 142 sujeitos, dentre os quais 64 professores ouvintes de escolas inclusivas, 62 surdos e 16 intérpretes de Libras, participantes do Curso de Formação de Professores em Tecnologias Digitais Acessíveis do Núcleo de Informática na Educação Especial (NIEE) da Universidade Federal do Rio Grande do Sul (UFRGS), que é oferecido gratuitamente a professores da educação básica que atuam em escolas públicas de todo o Brasil. As narrativas produzidas por esses sujeitos em relação à validade social dos aplicativos tradutores de Língua Portuguesa para Libras foram analisadas a partir da Técnica de Análise Textual Discursiva, conforme Moraes (2003).

Diante das constatações obtidas, a partir da análise textual dessas narrativas, foram investigadas as funcionalidades dos aplicativos HandTalk e ProDeaf Móvel com base nos cinco princípios propostos por Mayer e Moreno (2002) na perspectiva da Teoria da Aprendizagem Multimídia Apoiada por computador.

De maneira complementar, aplicou-se uma avaliação heurística, técnica de inspeção de usabilidade proposta por Nielsen (1994), para encontrar problemas de usabilidade no design. Esse método orienta avaliadores em um processo sistemático para encontrar problemas que prejudicam a usabilidade usando um conjunto de diretrizes (Barbosa e Silva, 2010). Três pesquisadores, número suficiente segundo Barbosa e Silva (2010), avaliaram os elementos da interface de ambos os aplicativos com base nas heurísticas de usabilidade de Nielsen (1994), registrando individualmente os problemas e, posteriormente, os consolidando em um relatório conjunto, abrangente e consensual. Esses e outros resultados serão apresentados nas próximas seções. 


\section{ANÁLISE E DISCUSSÃO DOS DADOS}

$\mathrm{Na}$ busca por Tecnologias Assistivas potencialmente mediadoras da construção do conhecimento, da subjetivação e da autonomia, identificou-se no ano de 2013, o surgimento no mercado brasileiro de aplicativos para dispositivos móveis, de duas ferramentas, ambas voltadas para a inclusão social: HandTalk e ProDeaf Móvel, tradutores automáticos de palavras, termos e pequenas frases da Língua Portuguesa para a Libras. Em um levantamento anterior (Vieira et al., 2014) não foram evidenciados aplicativos similares além dos aplicativos supracitados.

Alguns de seus requisitos e principais funcionalidades são: compatibilidade com diversos sistemas operacionais móveis (Android, iOS, Blackberry OS e Windows Phone 8), dependência de conexão à Internet móvel ou sem fio para funcionamento completo, entrada de dados por meio de texto escrito, falado ou fotografado, visualização da sinalização em diferentes ângulos, ajustes de velocidade de sinalização, notificação de erros e envio de sugestões aos desenvolvedores.

\section{1 “Quero aprender Libras no meu celular”}

A análise textual discursiva das narrativas dos sujeitos envolvidos neste estudo com relação à aprendizagem da Língua Portuguesa ou da Libras por meio de aplicativos tradutores automáticos permitiu a emergência de cinco categorias, com incidências diferentes para os públicos surdo e ouvinte, duas das quais referentes apenas a um dos grupos, conforme o Gráfico 1. No que se refere aos sujeitos ouvintes, as categorias de maior incidência estão relacionados ao uso de tais ferramentas para a aprendizagem ou ampliação do vocabulário em Língua Portuguesa para os usuários surdos e em Libras, para usuários ouvintes. Sujeitos ouvintes mencionaram ainda as possibilidades de utilização dos aplicativos para aprendizagem ou incremento do vocabulário da Libras para usuários surdos e, ainda, na capacitação de professores ouvintes que atuam em escolas inclusivas. "Poderei usar com aluno [surdo] em alguma atividade da Língua portuguesa, para aqueles que tem dificuldade em escrever em portugues e não são oralizados.” (professora ouvinte atuando em escola inclusiva). "Esse aplicativo é muito bom, pois atende tanto o ouvinte que quer aprender a língua, quanto aos surdos, que às vezes não tem fluência em língua portuguesa, ou até mesmo na LIBRAS” (sujeito intérprete de Libras).

As narrativas dos sujeitos surdos incluem, por ordem de incidência, possibilidade de apoio e mediação da aprendizagem e/ou da ampliação de vocabulário da Libras para usuários surdos e/ou ouvintes; apoio e mediação da aprendizagem e/ou da ampliação de vocabulário da Língua Portuguesa para usuários surdos e ainda; apoio e mediação a familiares ouvintes de pessoas surdas na aprendizagem e/ou da ampliação de vocabulário em Libras. "Se minha mãe e meus irmãos aprenderem Libras com esse aplicativo, eu prometo aprender o português também” (sujeito surdo - texto transcrito da Libras para o Português pela professora mediadora da atividade). "Conhecer aplicativo curso com minha irmã e gostar porque ter muitos sinais que precisar usar e não ter muitos cursos para aprender mais sinais novos. Usar agora sempre no tablet e usar quando esquecer também quando alunos querer aprender mais. Muito bom, adorei" 1 . (sujeito surdo). "O ProDeaf me ajuda no português. Tem palavra que não sei no português e pesquiso no ProDeaf” (sujeito surdo).

\footnotetext{
${ }^{1}$ Narrativas mantidas em relação à grafia original.
} 

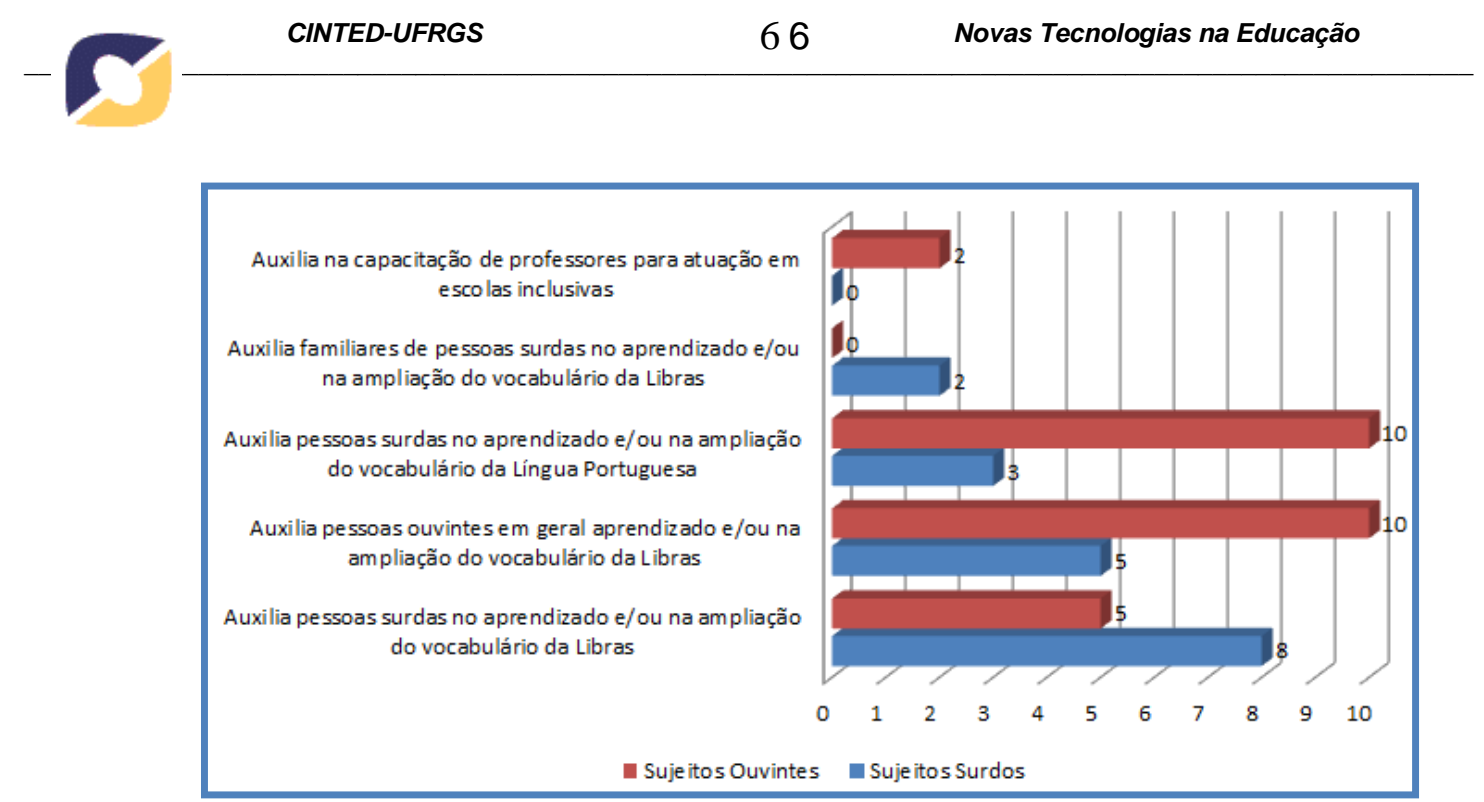

Gráfico 1: Categorias e incidências de discursos relacionados à aprendizagem por meio de tradutores automáticos de Língua Portuguesa para Libras

Observa-se, portanto, que enquanto para os sujeitos surdos a aprendizagem da Libras para os usuários surdos e ouvintes apresentou-se como a expectativa de uso mais significativa; sujeitos ouvintes demonstram a mesma intenção de que usuários surdos aprendam Língua Portuguesa e usuários ouvintes aprendam Libras. Com isso, percebe-se que os sujeitos surdos, enquanto pertencentes a uma minoria linguística (Quadros, 2008), interessam-se mais significativamente pela concretização social de sua língua do que pela inclusão mediada pela Língua Portuguesa, embora essa também tenha sido uma categoria apontada pelo grupo. Também observa-se o interesse de alguns dos professores ouvintes, sujeitos de pesquisa, pela consolidação de políticas públicas e educacionais (Brasil, 2005) referentes à inclusão de estudantes surdos em escolas comuns pela via do bilinguismo e não do aprendizado exclusivamente por meio da Língua Portuguesa.

\subsection{Contribuições da Teoria da Aprendizagem Multimídia}

Os autores Mayer e Moreno (2003) não preveem, em sua Teoria da Aprendizagem Multimídia, as características constitutivas do processo de aprendizagem de pessoas com deficiência sensorial visual ou auditiva. Schnotz (2005), entretanto, ressalta que é possível que outros canais sensoriais introduzam informação à memória de trabalho verbal, com a leitura do Braille por meio dos dedos, ou a leitura visual do movimento dos lábios. Por isso, faz-se aqui uma proposta de interpretação da dinâmica proposta na Teoria para o percurso da informação, segundo as características sensoriais das pessoas surdas.

Uma discussão possível a esse respeito pode partir do princípio de que, como pessoas surdas não podem obter memória sensorial auditiva, as informações presentes em materiais multimídia destinados esses estudantes devem ser apresentadas, exclusivamente, por meio do canal visual. É a partir do processamento na memória de trabalho, entretanto, que informações verbais (sejam textos ou os sinais gestuais-visuais da Libras) serão interpretados pelo modo verbal e, as demais imagens, pelo modo pictórico. A entrada de informação essencialmente por meio visual não significará, portanto, que essas serão interpretadas pelo modo pictórico uma vez que a Libras, embora de natureza gestual visual, apresenta função e complexidades específicas da linguística (Quadros, 2003; 2008).

Feitas essas primeiras considerações, e partir das diretrizes apresentadas pelos cinco princípios da Teoria da Aprendizagem Multimídia, infere-se que, para potencializar as 
possibilidades de aprendizagem da Língua Portuguesa e da Libras a usuários surdos e ouvintes por meio de aplicativos que envolvam avatares tradutores automáticos, as sinalizações gestuais-visuais apresentadas pelo avatar animado devem disponibilizar, de modo concomitante, narração ou texto equivalente em Língua Portuguesa. É essencial, contudo, que a interface da tela de sinalização disponibilize ao usuário as opções de (1) exibir apenas texto escrito ou (2) apenas narração.

No que concerne aos usuários ouvintes, isso se faz relevante por que a atual forma de apresentação de informação nos aplicativos analisados, quanto ao texto escrito associado aos sinais gestuais discordam do princípio da Modalidade; logo, a possibilidade de acesso concomitante à narração e aos sinais gestuais correspondentes, atenderia aos princípios da Contiguidade e da Multimídia, posto que animações narradas são mais efetivas à aprendizagem de pessoas ouvintes.

A respeito dos usuários surdos, pode-se considerar que, enquanto a apresentação do texto escrito em concomitância com os sinais gestuais-visuais não é adequada aos usuários ouvintes (princípio da Redundância), ela é necessária aos usuários surdos. Embora a entrada de informações concomitantes e complementares por um mesmo canal (no caso das pessoas surdas, os olhos) possa incorrer no que Sweller (2002) define como Efeito da Atenção Dividida - quando informações concomitantes competem pela atenção do receptor em um mesmo canal - essa parece ser a principal alternativa para prover ao surdo a contiguidade entre a informação apresentada em Libras e em Língua Portuguesa. A inserção da possibilidade de opção pelo texto escrito pode ser, portanto, compreendida como uma ação em caráter de acessibilidade.

\subsection{Avaliação Heurística de Usabilidade}

Conforme indicado na metodologia desse estudo, os três avaliadores inspecionaram individualmente cada software e compilaram suas descobertas em um relatório conjunto. Durante a consolidação desse relatório, os problemas de usabilidade encontrados foram classificados segundo as dez heurísticas de Nielsen (1994) e receberam um nível de gravidade, ou seja, a relação entre a frequência daquele problema e seu impacto para os usuários. Segundo Nielsen, o julgamento da gravidade se dá pela escala: (1) problemas cosméticos que não necessitam ser consertados, mas podem melhorar a experiência do usuário; (2) problemas leves que representam ruído (como leve redução de eficiência) na realização de uma tarefa e que devem ser corrigidos com prioridade baixa; (3) problemas graves que geram obstáculos significativos - embora contornáveis - na interação e que devem ser consertados; e (4) problemas catastróficos refletem barreiras instransponíveis que impedem completamente a realização de uma ou mais tarefas e devem ser imediatamente corrigidos. O Gráfico 2 apresenta um panorama geral da quantidade de problemas encontrados nos softwares ProDeaf Móvel e HandTalk.

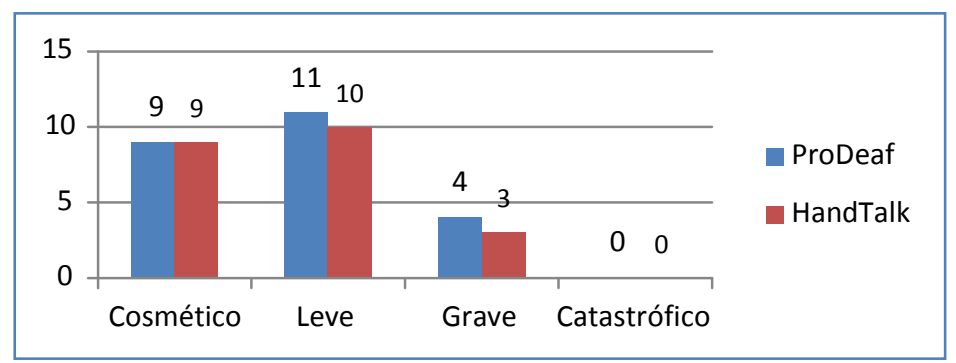

Gráfico 2: Quantidade de problemas de usabilidade encontrados e seus níveis de gravidade. 
Embora nenhum problema catastrófico tenha sido encontrado, os problemas graves são suficientemente inconvenientes para serem apresentados e terem sugestões de correção elencadas nessa pesquisa.

\subsubsection{Problemas de usabilidade graves no ProDeaf Móvel}

Não poder pausar a sinalização do avatar foi classificado como um problema de controle e liberdade do usuário, pois impede que o usuário desvie temporariamente sua atenção do software sem ter que reproduzir novamente a tradução no caso de ter perdido algum sinal. Isso poderia ser remediado com um botão de pausa disponibilizado durante a sinalização.

Ao iniciar a funcionalidade de reconhecimento de fala para tradução em Libras e não falando nada no microfone do dispositivo, o ProDeaf Móvel informa a mensagem "Por favor, conecte-se à internet para usar o reconhecimento de voz" mesmo quando o dispositivo está conectado à Internet. Esse problema evidente de ajudar a reconhecer e diagnosticar erros gera confusão para o usuário que tentará corrigir problemas de conexão quando, na realidade, o problema ocorreu ao capturar o som da voz. A mudança da mensagem de erro seria suficiente para resolver o problema.

Durante o tutorial, na apresentação das funcionalidades do software, o texto e a sinalização em Libras apresentam as funções fora da ordem da visualização na tela. Essa questão de consistência e padrões pode levar o usuário a tentar utilizar funções descompassadas de seus objetivos reais, sendo que a correção desse problema exige apenas reformulação da ordem do texto e da sinalização.

Quando o usuário escolhe notificar um erro de sinalização sem estar conectado à Internet, nenhuma mensagem de sucesso ou falha é exibida, estabelecendo um problema de visibilidade do estado do sistema. Uma sugestão simples de correção é a inclusão de uma mensagem com feedback adequado do resultado da tarefa: "Notificação de erro não enviada por você não estar conectado à Internet" ou "Notificação de erro registrada no dispositivo. Aguardando uma conexão com a Internet para finalizar o envio”.

\subsubsection{Problemas de usabilidade graves no HandTalk}

A funcionalidade de tradução do software HandTalk é limitada a 140 caracteres. Isso, por si só, não representa um problema de usabilidade, contudo, ao utilizar o reconhecimento de fala do software, não há indicativo de que a quantidade de texto reconhecido ultrapassou os 140 caracteres permitidos. Assim, qualquer palavra que exceda esse limite simplesmente não é sinalizada, caracterizando um problema grave de prevenção de erros. Correções possíveis incluem mostrar quais partes do texto serão sinalizadas e quais serão ignoradas e apresentar uma mensagem informativa ao usuário.

Aqui se repete o mesmo problema de apresentar textualmente as funcionalidades fora da ordem de apresentação visual no tutorial. A classificação como problema de consistência e padrões e a sugestão de correção são idênticas.

Embora a funcionalidade essencial de notificar erros de sinalização seja disponibilizada em duas telas distintas do software, nenhuma delas apresenta-se como um local claro e adequado. Para ter acesso à operação de notificação, devemos (1) acessar o histórico de traduções do aplicativo e selecionar uma frase ou (2) acessar o menu de opções e enviar o pedido de correção como uma sugestão. Isso representa um problema de flexibilidade e eficiência de uso, podendo ser solucionado pela inclusão de uma opção de notificar erro de sinalização logo após a sinalização ser reproduzida. 


\section{CONSIDERAÇÕES FINAIS}

A consolidação de ações inclusivas referentes a pessoas surdas deve envolver estratégias de ampliação da visibilidade, do conhecimento e do alcance da Libras, enquanto língua, ferramenta psicológica e aspecto da constituição identitária desses sujeitos. Nos espaços escolares, por exemplo, toda ação educativa que vise à inclusão de estudantes com deficiência auditiva deve priorizar as interações e mediações estabelecidas por meio da língua materna. Esses aspectos foram corroborados pelos sujeitos dessa pesquisa, ao apresentar expectativas de uso de aplicativos tradutores automáticos de Língua Portuguesa para Libras relacionados à aprendizagem de um ou de ambos os códigos linguísticos envolvidos. Tal postura não apenas reafirma a validade social dessas ferramentas digitais, como suscita interesses para que as mesmas apresentem vieses e funcionalidades mais alinhadas ao processo cognitivo humano no que concerne à construção de conhecimento.

A Teoria da Aprendizagem Multimídia fornece elementos que podem contribuir para a projeção de uma ferramenta automática de tradução mais adequada às características inerentes ao processo de aprendizagem de pessoas que não apresentam deficiência sensorial, no entanto, mostra-se pouco abrangente quanto ao mesmo processo em pessoas cujo canal de processamento auditivo encontra-se impossibilitado de receber informações. Ainda que o fornecimento de sinais gestuais-visuais em concomitância com texto escrito possa incorrer na sobrecarga do canal de processamento visual, esse apresenta-se como a alternativa viável à contiguidade na apresentação desse conteúdo como forma didática de aprendizagem multimídia da Língua Portuguesa para pessoas surdas. O oferecimento de narrações ou texto escrito contíguos à sinalização pode ser uma maneira de atender às necessidades de ouvintes e de surdos, desde que seja possibilitada sua desabilitação.

No que tange à usabilidade, o processo de engenharia deve ser contínuo, desde o início do desenvolvimento do sistema. Pelos resultados obtidos na avaliação dessa pesquisa, a ausência de problemas catastróficos e a pequena quantidade de falhas encontradas em aplicativos tão complexos revelam um esforço para manter a qualidade da interação em ambos os softwares. Contudo, problemas graves ainda foram detectados em uma avaliação simples e de baixo custo e evidenciam pontos relevantes de melhoria nos aplicativos. Essa manutenção possibilitará aprimoramento no uso de suas funcionalidades e impulsionará a experiência positiva de usuários surdos e ouvintes. Frente a outras considerações feitas pelos sujeitos desta pesquisa com relação a aplicativos tradutores da Língua Portuguesa para Libras, trabalhos futuros poderão envolver análises linguísticas do processo de sinalização automática.

\section{Referências Bibliográficas}

BAKHTIN, M. Marxismo e Filosofia da Linguagem. Hucitec $12^{\text {a }}$ Ed.,2006

BARBOSA, S., SILVA, B. S. Interação humano-computador. Rio de Janeiro: Elsevier, 2010.

BARTH, C., SILVA, A. A., SANTAROSA, L. M. C. Aquisição da Escrita de Sinais por Crianças Surdas através de Ambientes Digitais. RENOTE - Revista Novas Tecnologias na Educação, v. 5, n. 2, p. 112, 2007.

BASTIEN, J. M. C., SCAPIN, D. L. Ergonomic criteria for the evaluation of human-computer interfaces. Technical report N. 156. INRIA, 1993.

BENVENISTE, E. Problemas de Linguística Geral II. Campinas: Pontes, 1989. 
BRASIL. Decreto n 5.626, de 22 de dezembro de 2005. Diário Oficial da União. Brasília, DF, 23 dez 2005.

Lei n.10.436, de 24 de abril de 2002. Dispõe sobre a Língua Brasileira de Sinais - Libras e dá outras providências. Diário Oficial da União, Brasília, DF, 25 abr. 2002.

CAPOVILLA, F.C. e CAPOVILLA, A.G.S. Educação da criança surda: o bilinguismo e o desafio da descontinuidade entre a língua de sinais e a escrita alfabética. Revista Brasileira de Educação Especial, Universidade Estadual Paulista, V.8, n.2, 2002.

CORRÊA, Ygor ; VIEIRA, M. C. ; SANTAROSA, Lucila M. Costi ; BIAZUS, M. C. V. . Tecnologia Assistiva: a inserção de aplicativos de tradução na promoção de uma melhor comunicação entre surdos e ouvintes. RENOTE. Revista Novas Tecnologias na Educação, v. 12, p. 1-10, 2014.

ISO 9241-11: Ergonomic requirements for office work with visual display terminals (VDTs) part 11: Guidance on usability. ISO, 1998.

ISO/IEC 9126: Software engineering - product quality. ISO, 1991.

MAYER, R. E.; MORENO, R. Aids to computer-based multimedia learning. Learning and Instruction, v. 12, p. 107-119, 2002.

. Nine Ways to Reduce Cognitive Load in Multimedia Learning. Educational Psychologist, 38 (1), 43-52, 2003.

MORAES, R. Uma tempestade de luz: a compreensão possibilitada pela análise textual discursiva.

Ciência Educação, Bauru, SP, v. 9, n. 2, p. 191-210, 2003.

MORAN, T. The Command Language Grammars: a representation for the user interface of interactive computer systems. In: International Journal of Man-Machine Studies, 15:3-50, Academic Press, 1981.

NIELSEN, J. Heuristic Evaluation. In: NIELSEN, J.; MACK, R. L. Usability Inspection Methods. New York: John Wiley and Sons, 1994.

QUADROS, R. M. de. Educação de surdos: a aquisição da linguagem. Porto Alegre: Artmed, 2008.

. Situando as diferenças implicadas na educação de surdos: inclusão/exclusão. Ponto de Vista, Florianópolis, n.05, 2003, p. 81-111.

SANTAROSA, L. M. C.; CONFORTO, D. Formação de Professores: Construindo Cenários Inclusivos. RENOTE - Revista Novas Tecnologias na Educação, v. 8, n. 1, 2010.

SANTOS, L. M. A.; TAROUCO, L. M. R.. A importância do estudo da Teoria da Carga Cognitiva em uma Educação Tecnológica. Renote - Revista Novas Tecnologias na Educação, V. 5 No 1, julho de 2007.

SCHNOTZ, W. An integrated model of text and Picture comprehension. In: MAYER, R.E. (ed.), Cambridge Handbook of Multimedia Learning. Cambridge: Cambridge University Press, 2005. Pp. 4969.

SWELLER, J. Visualisation and Instructional Design. In: Proceedings of the International Workshop on Dynamic Visualizations and Learning. Tübingen, Alemanha, 18-19 de julho, 2002.

VIEIRA, M. C. ; CORRÊA, Ygor ; SANTAROSA, Lucila M. Costi ; BIAZUS, M. C. V. . Análise de expressões não-manuais em avatares tradutores de Língua Portuguesa para Libras. In: XIX Conferência Internacional sobre Informática na Educação - TISE, 2014, Fortaleza. Nuevas Ideas en Informática Educativa, 2014. v. 10. p. 172-183.

VYGOTSKY, L.S. Obras Completas: fundamentos da defectologia. Tomo V. Trad. Ma. del Carmen Ponce Fernández. Ciudad de La Habana: Editorial Pueblo y Educación, 1997. 